\title{
Kinetic Study of Thermal Degradation of High-impact Polystyrene Nanocomposites with Different Flame Retardants using Isoconversional and Model Fitting Methods
}

\author{
Zvonimir Katančić, ${ }^{1, *}$ Ivana Grčić, ${ }^{2, \#}$ Zlata Hrnjak-Murgić1
}

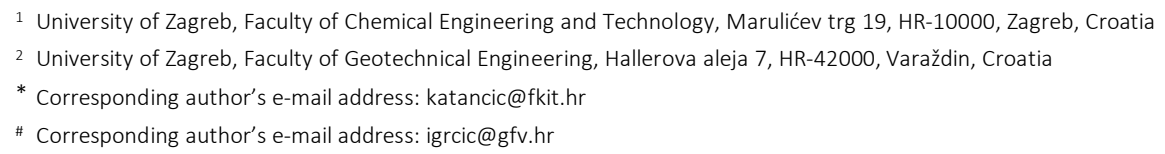

\# Corresponding author's e-mail address: igrcic@gfv.hr

RECEIVED: February 23, 2017 * REVISED: May 22, 2017 * ACCEPTED: June 02, 2017

\begin{abstract}
The non-isothermal degradation of pure high-impact polystyrene (HIPS) and flame retarded HIPS nanocomposites was investigated in the temperature range $25-550{ }^{\circ} \mathrm{C}$ at four heating rates in an inert atmosphere. Three different phosphate and polyphosphate based flame retardants were used, while nanosilica and montmorillonite clay were used as nanofillers. Kinetic analysis was performed using isoconversional and model fitting non-linear regression method. Activation energy $\left(E_{a}\right)$ was determined by isoconversional methods of Friedman and KissingerAkahira-Sunose while true kinetic triplets $\left(E_{a}, A, f(\alpha)\right)$ were determined by one step and two-step non-linear regression with various reactions mechanisms. It was found that flame retarded samples exhibit complex degradation which cannot be satisfactorily described by single reaction model fitting. Instead, when each distinctive degradation step was modelled individually it was possible to obtain good fit with Reaction order and Avrami-Erofeev proposed mechanisms while the same was not possible for Diffusion and Autocatalytic mechanisms.
\end{abstract}

Keywords: flame retardants, high-impact polystyrene, non-isothermal degradation kinetics, nonlinear regression, thermogravimetric analysis.

\section{INTRODUCTION}

$\mathbf{H}$ GH-IMPACT polystyrene (HIPS) is well-known copolymer of polystyrene and polybutadiene (PB) rubber with the increased impact strength and toughness compared to glassy polystyrene (PS). Due to its chemical constitution HIPS is highly flammable and therefore different flame retardants (FR) are added to HIPS to reduce its flammability which has been described in many studies. ${ }^{[1-5]}$ Addition of flame retardants to polymers increases their flame resistance but also changes kinetics of decomposition which has been in focus of many papers. ${ }^{[6-}$ 10] The kinetic modelling of the decomposition is crucial for an accurate prediction of the materials behaviour under different working conditions. ${ }^{[11-14]}$ Therefore, the kinetic analysis also provides some understanding of the mechanism of the reaction under study. ${ }^{[15-17]}$ Knowledge of the mechanism of thermal degradation of available macromolecules is very helpful in the field of the thermal stability of polymers. ${ }^{[18]} \mathrm{A}$ reliable evaluation of the kinetic parameters permits a theoretical interpretation of the experimental data and provides a mathematical descripttion needed to extrapolate the reaction behaviour to conditions different from the experimental ones. ${ }^{[19,20]}$ The pyrolysis of organic materials, such as polymers, is a chemically complex process, where several reactions may be occurring simultaneously. ${ }^{[21-23]}$ Because of this complexity, most of the papers focused on polymer degradation kinetics assume "n-order" kinetic models, $[8,24-27]$ without any guarantee that these empirical conversion functions can actually describe correctly the real polymer degradation reaction leading to erroneous kinetic parameters. 
Table 1. Kinetic mechanisms used in model fitting methods

\begin{tabular}{|c|c|c|}
\hline Mechanism & Symbol & $f(\alpha)$ \\
\hline Reaction order & Fn & $(1-\alpha)^{n}$ \\
\hline $\begin{array}{l}\text { Random nucleation and growth of nuclei } \\
\text { (Avrami-Erofeev) }\end{array}$ & An & $\mathrm{n}(1-\alpha)[-\ln (1-\alpha)]^{(1-1 / n)}$ \\
\hline Autocatalytic reaction & Ac & $\alpha^{m}(1-\alpha)^{n}$ \\
\hline 1D diffusion (parabolic law) & $1 \mathrm{D}$ & $1 / 2 \alpha$ \\
\hline 2D diffusion (bidimensional particle shape) & $2 \mathrm{D}$ & $1 /[-\ln (1-\alpha)]$ \\
\hline $\begin{array}{c}\text { Reaction on phase boundary (cylindrical } \\
\text { symmetry) }\end{array}$ & R2 & $(1-\alpha)^{1 / 3}$ \\
\hline $\begin{array}{c}\text { Reaction on phase boundary (spherical } \\
\text { symmetry) }\end{array}$ & R3 & $(1-\alpha)^{2 / 3}$ \\
\hline
\end{tabular}

Thermogravimetric analysis, in inert or in reactive conditions at different temperature versus time programs, both isothermal and dynamic, is extensively used in studies of polymers thermal degradation. The use of methods that use single heating rate data for the determination of the kinetic parameters should be avoided[28] because they generally cannot distinguish true from false kinetic model and tend to produce highly uncertain values of activation energy $\left(E_{\mathrm{a}}\right)$ and pre-exponential factor $A$. The multiple heating rate, model-free, methods provide good estimates of activation energy. ${ }^{[29]}$

The objective of this work was to study nonisothermal degradation mechanisms and kinetics of the flame-retarded HIPS polymer with different types of phosphate and polyphosphate flame retardants. As the first step, dependence of activation energy on conversion $(\alpha)$ was established by isoconversional methods. This was followed by nonlinear regression modelling in single or multistep kinetics according to distinct proposed reaction mechanisms in order to determine true factor $(A)$ and reaction model, $f(\alpha)$.

\section{KINETIC THEORY}

In order to study thermal decomposition of high-impact polystyrene nanocomposites with different flame retardants kinetic analysis of the degradation process was performed. The reaction rate $(\mathrm{d} \alpha / \mathrm{d} t)$ of solid state reaction at non-isothermal conditions at constant heating $(B=\mathrm{d} T / \mathrm{d} t)$ rate can be described by following Arrhenius equation:

$$
\frac{\mathrm{d} \alpha}{\mathrm{d} t}=\beta \frac{\mathrm{d} \alpha}{\mathrm{d} T}=A \exp \left(\frac{-E_{\mathrm{a}}}{R T}\right) f(\alpha)
$$

where $\alpha$ is conversion degree defined as the ratio of the actual weight loss to the total weight loss, $B$ heating rate, $A$ Arrhenius pre-exponential factor or frequency factor, $E_{\mathrm{a}}$ activation energy, $R$ the gas constant, $T$ is the absolute temperature and $f(\alpha)$ is the reaction rate dependence on $\alpha$.
Activation energy, the pre-exponential factor and kinetic model are called the "kinetic triplet". The kinetic model, $f(\alpha)$, is an algebraic expression which is usually associated with a physical model that describes the kinetics of the solid state reaction. Various kinetic models could be found in literature and some of the most commonly used are used in this work and are listed in Table 1.

Isoconversional methods (model-free methods) are used for determination of the activation energy as a function of the reacted fraction without any previous assumption on the kinetic model fitted by the reaction. Model-free methodology has long proved useful to obtain reliable kinetic information on many different processes. The fundamental assumption of the model-free method is that the reaction model $f(\alpha)$ is not dependent on temperature or heating rate. ${ }^{[13]}$ In this work, two different isoconversional methods, the differential Friedman method and the integral Kissinger-Akahira-Sunose method ${ }^{[30]}$ were used to determine the apparent Ea. The Friedman isoconversional method ${ }^{[31]}$ is a widely used differential method that, unlike conventional integral model-free methods, provides accurate values of activation energies even if the activation energy is a function of the reacted fraction. The method is derived simply expressing Eq. (1) in logarithmic form yielding:

$$
\ln \left[8 \frac{\mathrm{d} \alpha}{\mathrm{d} T}\right]=\ln A+\ln f(\alpha)-\frac{E_{\mathrm{a}}}{R T}
$$

Kissinger-Akahira-Sunose (KAS) is a linear integral method based on equation:

$$
\ln \frac{B}{T^{2}}=\ln \frac{A R}{E_{\mathrm{a}} g(\alpha)}-\frac{E_{\mathrm{a}}}{R T}
$$

After the values of the activation energy have been calculated with the use of the isoconversional methods, the determination of reaction model $f(\alpha)$ was performed using model fitting multivariate non-linear regression method. The iterative procedures were used to estimate kinetic 
Table 2. Composition of prepared samples in mass $\%$

\begin{tabular}{cccccc}
\hline Sample & HIPS & $\mathrm{SiO}_{2}$ & DPO & AP766 & OP1312 \\
\hline PS & 100 & - & - & - & - \\
PS-8A-8P & 84 & 8 & 8 & - & - \\
PS-4A-20AP & 76 & 4 & - & 20 & - \\
PS-4A-20OP & 76 & 4 & - & - & - \\
PS-20AP-4C & 76 & - & - & 20 & - \\
\hline
\end{tabular}

triplet. The degradation kinetics parameters were evaluated with the use of the Wolfram Mathematica 8.0 software.

\section{EXPERIMENTAL}

\subsection{Materials}

High-impact polystyrene (HIPS Doki 472, melt index $3.5 \mathrm{~g} /$ $10 \mathrm{~min}$ at $200{ }^{\circ} \mathrm{C} / 5 \mathrm{~kg}$ ), was obtained from Dioki, Croatia. Ammonium polyphosphate (Exolit AP 766, phosphorus content 23-25 mass \%, nitrogen content 14.4-16.4 mass \%) and organic polyphosphate (Exolit OP 1312, phosphorus content 17.8-19.7 mass \%) were supplied by Clariant while organically modified natural clay, montmorillonite (MMT, Closite 20A, $d_{001}$ distance $2.42 \mathrm{~nm}$ ) was supplied from Rockwood additives. Methacrylsilane surface modified fumed silica $\left(\mathrm{SiO}_{2}\right)$ was obtained from Evonik Industries (Aerosil R7200, $\mathrm{SiO}_{2}$ content $99.8 \%$, particle size $12 \mathrm{~nm}$ ) while Diphenyl 2-ethiylhexylphosphate (disflamoll DPO, phosphorus content of 8.6 mass \%) was produced by Lanxess. Chemicals were used as received without any further purification or modification.

\subsection{Sample Preparation}

All samples were prepared by melt blending in rotating twin screw extruder at slightly different conditions. ${ }^{[1,3,32]}$ Compositions of studied samples are listed in Table 2.

\subsection{Thermogravimetric Analysis (TGA)}

Thermogravimetric analysis was performed using a TA Instruments Q500. The TGA experiments have been carried out in nitrogen atmosphere from 25 to $550{ }^{\circ} \mathrm{C}$ at four heating rates: $5,10,15$ and $20^{\circ} \mathrm{C} / \mathrm{min}$. The sample weights were ca $10 \mathrm{mg}$, while gas flow was $100 \mathrm{ml} / \mathrm{min}$. Three replicates were run for each sample and the average value was reported. Uncertainty of initial mass loss and maximum loss rate temperatures was less than $2.7^{\circ} \mathrm{C}$ while char residue uncertainty was 1.9 mass $\%(2 \sigma)$.

\subsection{Morphology Characterization}

To examine morphology of prepared samples scanning electron microscopy (SEM), transmission electron microscopy (TEM) and $x$-ray diffraction (XRD) were performed.

SEM pictures were made using a Philips XL30S FEG SEM at 5kV. Samples were sputter coated with Pt prior to measurement. XRD analyses were conducted at ambient temperature using a Rigaku Miniflex II X-ray diffractometer $\left(\left(\lambda\left(\mathrm{Cu}_{\mathrm{k \alpha}}\right)=1.5405 \AA\right)\right.$ XRD spectra were recorded in the $3^{\circ}$ $10^{\circ} 2 \Phi$ range with a step of $0.02^{\circ}$, a step time of $1.2 \mathrm{~s}$. For TEM pictures samples were ultra microtomed with a diamond knife on a Leica EM UC6 microtome. Sections were transferred to Cu grids of 400 mesh. Bright-field TEM images of nanocomposites were obtained at $120 \mathrm{kV}$ with a Philips CM12 electron microscope, using a Gatan 791 Bioscan CCD camera.

\section{RESULTS AND DISCUSSION}

\subsection{Morphology}

As all samples are prepared with nanoparticles $\left(\mathrm{SiO}_{2}\right.$ or MMT clay), which affect thermal properties as well as decomposition kinetics, morphology was examined by SEM for samples with $\mathrm{SiO}_{2}$ (PS-8A-8P, PS-4A-20AP and PS-4A20OP) while TEM and XRD were used for sample with nanoclay (PS-20AP-4C). SEM images of samples with $\mathrm{SiO}_{2}$ and different fire retardants are shown in Figure 1. As DPO fire retardant is liquid there are no microparticles in sample PS-8A-8P (Figure 1a) except $\mathrm{SiO}_{2}$ which cannot be clearly seen due to their nanosize. As only couple of small aggregates are visible it can be concluded that dispersion of $\mathrm{SiO}_{2}$ is generally very good. In Figures $1 \mathrm{~b}$ and $1 \mathrm{c}$ samples with ammonium polyphosphate and organic polyphosphate are shown. Since they are much larger their irregular shaped particles are visible. Again, $\mathrm{SiO}_{2}$ is visible only where some agglomerates were formed but it can also be concluded that dispersion of nanosilica in polymer matrix is satisfying.

Since the sample PS-20AP-4C contains nanoclay TEM and XRD were used as they are more suitable for their characterization and results are shown in Figure 2.

XRD spectra of pure montmorillonite clay and sample PS20AP-4C is shown in Figure 2b. Nanoclay exhibits a peak at $2 \Phi=3.5^{\circ}$ that corresponds to a $d_{001}$ spacing of $2.52 \mathrm{~nm}$ 

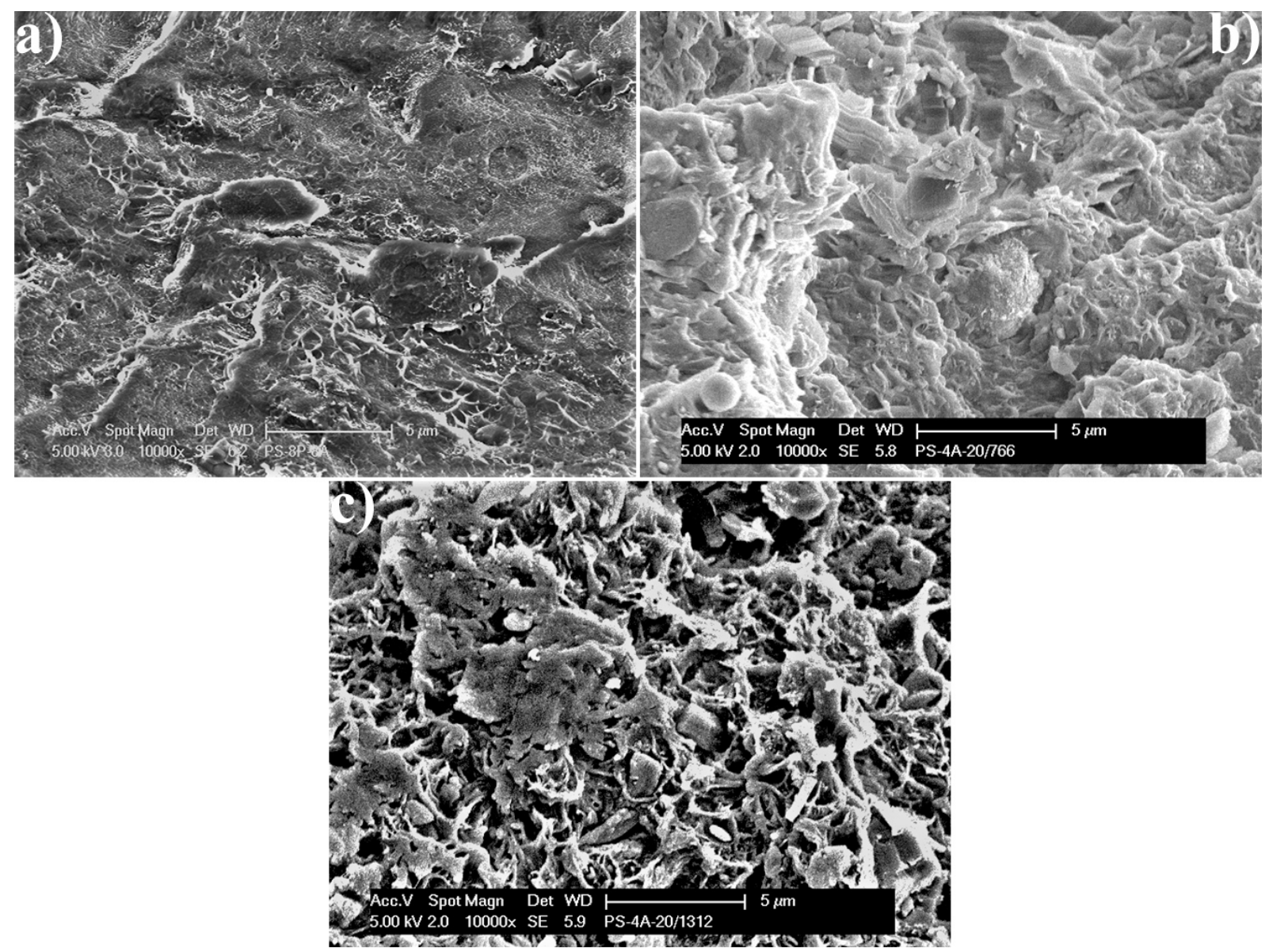

Figure 1. SEM images of sample a) PS-8A-8P, b) PS-4A-20AP and c) PS-4A-200P.

which is in a good agreement with suppliers specifications $(2.42 \mathrm{~nm})$.

For the prepared nanocomposite it can be seen that $d_{001}$ peak is shifted to the lower value indicating increase of interlayer distance of nanoclay. According to the Bragg's law $2 \Phi$ value of $3.1^{\circ}$ corresponds to an average interlayer distance of $2.85 \mathrm{~nm}$. Such increase in the distance between the platelets could be attributed to the intercalation of
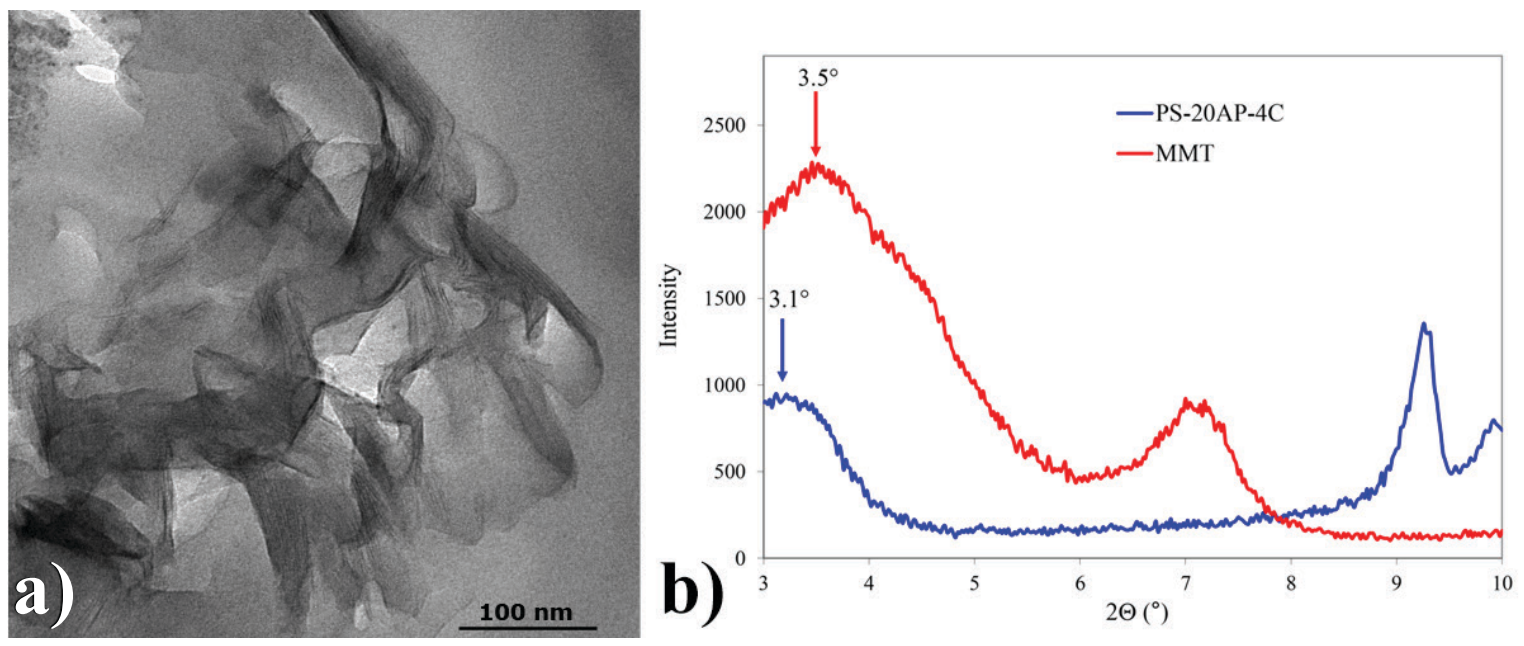

Figure 2. a) TEM picture, b) X-ray diffractogram for sample PS-20AP-4C[32]. 
Table 3. Temperatures at weight $\left(T_{90}-T_{20}\right.$ in $\left.{ }^{\circ} \mathrm{C}\right)$ and residual weight after pyrolysis at $500{ }^{\circ} \mathrm{C}\left(r_{500}{ }^{\circ} \mathrm{C}\right.$ in $\left.\%\right)$; heating rate $5{ }^{\circ} \mathrm{C} / \mathrm{min}$

\begin{tabular}{|c|c|c|c|c|c|c|c|c|c|}
\hline & $T_{90}$ & $T_{80}$ & $T_{70}$ & $T_{60}$ & $T_{50}$ & $T_{40}$ & $T_{30}$ & $T_{20}$ & $r_{500^{\circ} \mathrm{C}}$ \\
\hline PS & 390 & 404 & 411 & 416 & 421 & 425 & 429 & 434 & 1.1 \\
\hline PS-8A-8P & 341 & 413 & 424 & 430 & 435 & 440 & 444 & 448 & 6.8 \\
\hline PS-4A-20AP & 385 & 412 & 422 & 430 & 436 & 443 & 449 & 456 & 12.6 \\
\hline PS-4A-200P & 386 & 407 & 416 & 422 & 428 & 434 & 440 & 449 & 8.5 \\
\hline PS-20AP-4C & 377 & 410 & 420 & 428 & 434 & 441 & 448 & 458 & 20.2 \\
\hline
\end{tabular}

polymer chains into the clay galleries. TEM image, shown in Figure $2 \mathrm{a}$, reveals that mixed structure is present. While there are exfoliated and partially intercalated platelets visible, big tactoids without intercalation could be also observed. Generally it can be concluded that results obtained with TEM show very good match with XRD analysis. Although mixed structure is present, intercalated structure is dominant with the degree of intercalation of about $15 \%$.

\subsection{Isoconversional Methods}

As a first step for the kinetic calculation TGA was recorded at four heating rates and comparison of thermal stability of nanocomposites and pure HIPS is shown in Table 3 where results of $5{ }^{\circ} \mathrm{C} / \mathrm{min}$ heating rate are presented. It can be seen that pure HIPS starts to decompose around $390^{\circ} \mathrm{C}$ and at $434{ }^{\circ} \mathrm{C}$ only $20 \%$ of starting weight remains with final char residue at $500{ }^{\circ} \mathrm{C}$ just $1.1 \%$. All prepared nanocomposites start to degrade at 5 to $50{ }^{\circ} \mathrm{C}$ lower temperatures because fire retardants start to decompose before polymer matrix.

After initial faster decomposition of nanocomposites, at higher temperatures HIPS degradation proceeds faster and $T_{20}$ for nanocomposites is reached at 448 to 456 ${ }^{\circ} \mathrm{C}$ which is 14 to $22{ }^{\circ} \mathrm{C}$ above $T_{20}$ for HIPS. It is also visible that fire-retarded samples have high char residue, especially samples with ammonium polyphos-phate fire retardant (PS-4A-20AP and PS-20AP-4C). From TGA results it is clearly visible that nanocomposites have higher thermal stability despite lower degradation onset temperature.

The differential and integral isoconversional methods of Friedman and Kissinger-Akahira-Sunose were first used to determine the apparent $E_{\mathrm{a}}$ of all studied HIPS composites. These methods allow the acquisition of the apparent $E_{\mathrm{a}}$ from the slope of the isoconversional plots. Summarized results of $E_{\mathrm{a}}$ are given in Table 4. It can be observed that the values obtained using both isoconversional methods were nearly identical, Friedman method usually having 5 to $10 \mathrm{kJmol}^{-1}$ higher value of $E_{\mathrm{a}}$. Apparent $E_{\mathrm{a}}$ for HIPS degradation is nearly constant (around $270 \mathrm{kJmol}^{-1}$ ) in $\alpha$ region between 0.2 and 0.9. Such result is in agreement with literature ${ }^{[33,34]}$ and it is indication that from the kinetical point of view investigated process is simple (one-step process) and can be described by unique kinetic triplet. ${ }^{[28]}$ For the fire retarded composites it can be seen that reaction mechanism is more complex. For samples PS-8A-8P, PS-4A-20AP and PS-4A-200P $E_{\mathrm{a}}$ decreeses with conversion increase. According to general algorithm proposed by Vyzovkin and Lesnikovich ${ }^{[35]}$ such shape of $E_{\mathrm{a}}$ vs. $\alpha$ curve indicates complex mechanism which involves reversible stage or change of limiting stage reactions.

Table 4. Activation energies ( $E_{\mathrm{a}}$ in $\mathrm{KJ} \mathrm{mol}^{-1}$ ) of samples determined by Kissinger-Akahira-Sunose and Friedman isoconversional methods

\begin{tabular}{|c|c|c|c|c|c|c|c|c|c|c|}
\hline \multirow{2}{*}{$\alpha$} & \multicolumn{2}{|c|}{ PS } & \multicolumn{2}{|c|}{ PS-8A-8P } & \multicolumn{2}{|c|}{ PS-4A-20AP } & \multicolumn{2}{|c|}{ PS-4A-20OP } & \multicolumn{2}{|c|}{ PS-20AP-4C } \\
\hline & KAS & $F R$ & KAS & $F R$ & KAS & $F R$ & KAS & $F R$ & KAS & $F R$ \\
\hline 0.1 & 215.1 & 225.7 & & & 627.6 & 633.0 & 303.3 & 308.7 & 174.5 & 34.9 \\
\hline 0.2 & 259.5 & 265.1 & 314.1 & 319.8 & 263.3 & 268.9 & 242.2 & 247.9 & 192.1 & 197.7 \\
\hline 0.3 & 273.3 & 279.0 & 244.9 & 250.7 & 243.1 & 248.9 & 223.0 & 228.8 & 210.3 & 216.0 \\
\hline 0.4 & 276.5 & 282.2 & 223.2 & 229.0 & 233.1 & 238.9 & 212.4 & 218.2 & 213.2 & 218.9 \\
\hline 0.5 & 274.7 & 280.5 & 211.2 & 217.1 & 223.3 & 229.2 & 203.7 & 209.5 & 211.0 & 216.8 \\
\hline 0.6 & 272.0 & 277.1 & 202.2 & 208.1 & 212.4 & 218.4 & 197.2 & 203.1 & 206.1 & 212.0 \\
\hline 0.7 & 269.2 & 275.0 & 196.5 & 202.5 & 204.0 & 209.9 & 192.7 & 198.6 & 199.1 & 205.0 \\
\hline 0.8 & 276.0 & 281.9 & 191.1 & 197.0 & 196.2 & 202.2 & 190.6 & 196.6 & 192.1 & 198.1 \\
\hline 0.9 & 282.8 & 288.7 & 184.8 & 190.9 & 189.0 & 195.0 & 197.7 & 203.7 & 186.5 & 192.5 \\
\hline
\end{tabular}


For the sample PS-20AP-4C $E_{\mathrm{a}}$ at first increases with maximum around $\alpha=0.4$ followed by decrease, indicating again complex multi reaction mechanism involving parallel and reversible reactions. All fire retarded samples generally have lower average $E_{\mathrm{a}}$ values (in the region $\alpha=0.2-0.9$ ) than pure HIPS which could lead to conclusion that HIPS has higher thermal stability and slower degradation rate. Our previous studies ${ }^{[1,3,32]}$ show that is not the case. Since $E_{\mathrm{a}}$ is only one part of kinetic triplet, it is possible that difference in frequency factor, $A$, of composites compensates their lower $E_{\mathrm{a}}$ when compared to HIPS. ${ }^{[36]}$ Therefore it was necessary to determine $A$ and $f(\alpha)$. The $E_{\mathrm{a}}$ values that were obtained using the Friedman and Kissinger-Akahira-Sunose methods were used as a reference to assess the most probable kinetic model for each thermal decomposition process.

\subsection{Model Fitting Kinetics 4.3.1. ONE STEP MODELLING}

The true kinetic models of the different samples at different heating rates were determined by testing the kinetic models given in Table 2 on the experimental data and $E_{\mathrm{a}}$ obtained in section 4.2. Fitting was accomplished by means of nonlinear regression that minimizes the difference between the measured and calculated data. The difference was evaluated by the method of least squares in the form of root-mean-square-deviation (RMSD):

$$
\operatorname{RMSD}=\sqrt{\frac{\sum_{i=1}^{N}\left(x_{\text {exp }}-x_{\text {calc }}\right)^{2}}{N}}=\min
$$

The closest fit was assumed to give the best description of the degradation process. In mathematical terms, the optimization problem is posed as follows:

$$
\text { Objective function }=\min \sum_{i=1}^{N}\left|\frac{x_{\exp }-x_{\text {calc }}}{x_{\exp }}\right|
$$

where $N$ is the number of time steps for the model solution, and $x_{\exp }$ and $x_{\text {calc }}$ are experimental and model corresponding result solutions, respectively. The objective function has following variables: pre-exponential factor, parameters of model ( $m$ and $n$ for Ac, $n$ for An and Fn) and constrained values of activation energy which are optimized to match experimental weight fraction as function of time and temperature based on pre-set constant heating rate $(B)$ with model computed values. Flow chart of such modelling is shown in Figure 3.

At first, modelling of degradation of pure HIPS was performed. Figure 4 shows experimental and calculated data for all applied models. It can be seen that with diffusional and phase boundary kinetic models (1D, 2D, R2 and R3) it was impossible to obtain " $\mathrm{S}$ " shape of $\alpha$ - $t$ curve

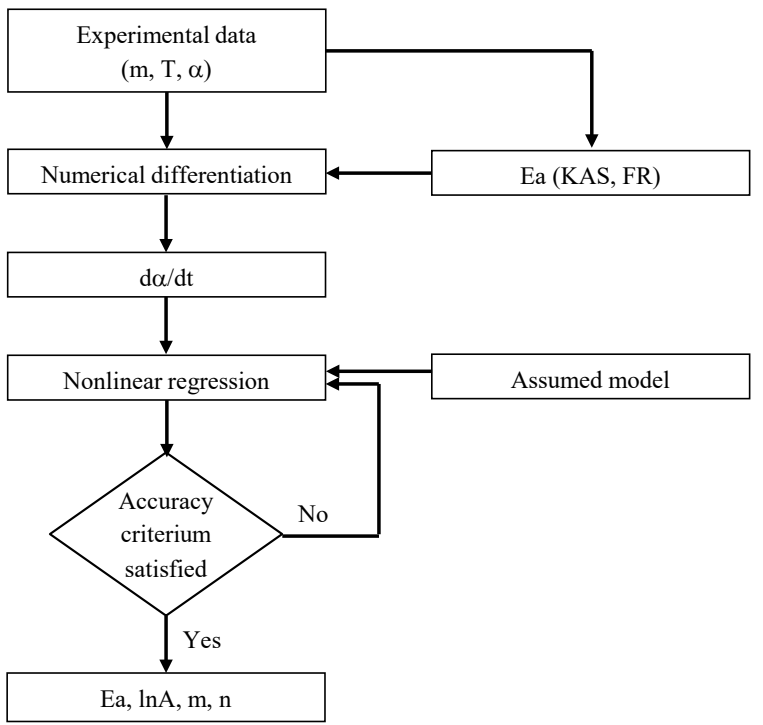

Figure 3. Flow chart of thermal degradation modelling with one model.

so they were excluded from modelling of composites degradation. Figure 5 shows Reaction order, AvramiErofeev and Autocatalytic mechanisms for sample PS-20AP$4 C$ and similar level of fit was achieved for other fire retarded composites. All kinetic parameters, including $E_{\mathrm{a}}$, $\ln A, f(\alpha)_{\text {true }}$ along with RMSD values for all samples are listed in Table 5. According to RMSD best fit for HIPS was achieved with Reaction order and Avrami-Erofeev mechanisms (around 0.014) while for Autocatalytic model RMSD was more than doubled. Activation energy was found to be between 261 and $268 \mathrm{kJmol}^{-1}$ for all models which is in a good agreement with $E_{\mathrm{a}}$ calculated by isoconversional methods. For composites best fit was again obtained for Fn and An mechanisms, while Ac had somewhat higher RMSD values. Generally it can be seen that with neither model it was possible to achieve level of fit as was for HIPS with RMSD values being approximately two to three times higher than for pure polymer. Figure 5 shows, as an example, comparison of experimental and models calculated data for all three used models for sample PS-20AP-4C.

Similar results were obtained for other composite samples. The main difference when compared with HIPS degradation is the shape of the curve at lower $\alpha$ values $(\alpha<$ 0.2 ) where simultaneous degradation of flame retardants and HIPS occurs. $E_{\mathrm{a}}$ values for composites were higher than one calculated by model-free methods. For instance, sample PS-20AP-4C has $E_{\mathrm{a}}$ between 180 and $220 \mathrm{~kJ} \mathrm{~mol}^{-1}$ according to KAS and Friedman method, while with model fitting $E_{\mathrm{a}}$ was between 226 (Autocatalytic model) and 265 $\mathrm{kJ} \mathrm{mol}^{-1}$ (Avrami-Erofeev). 

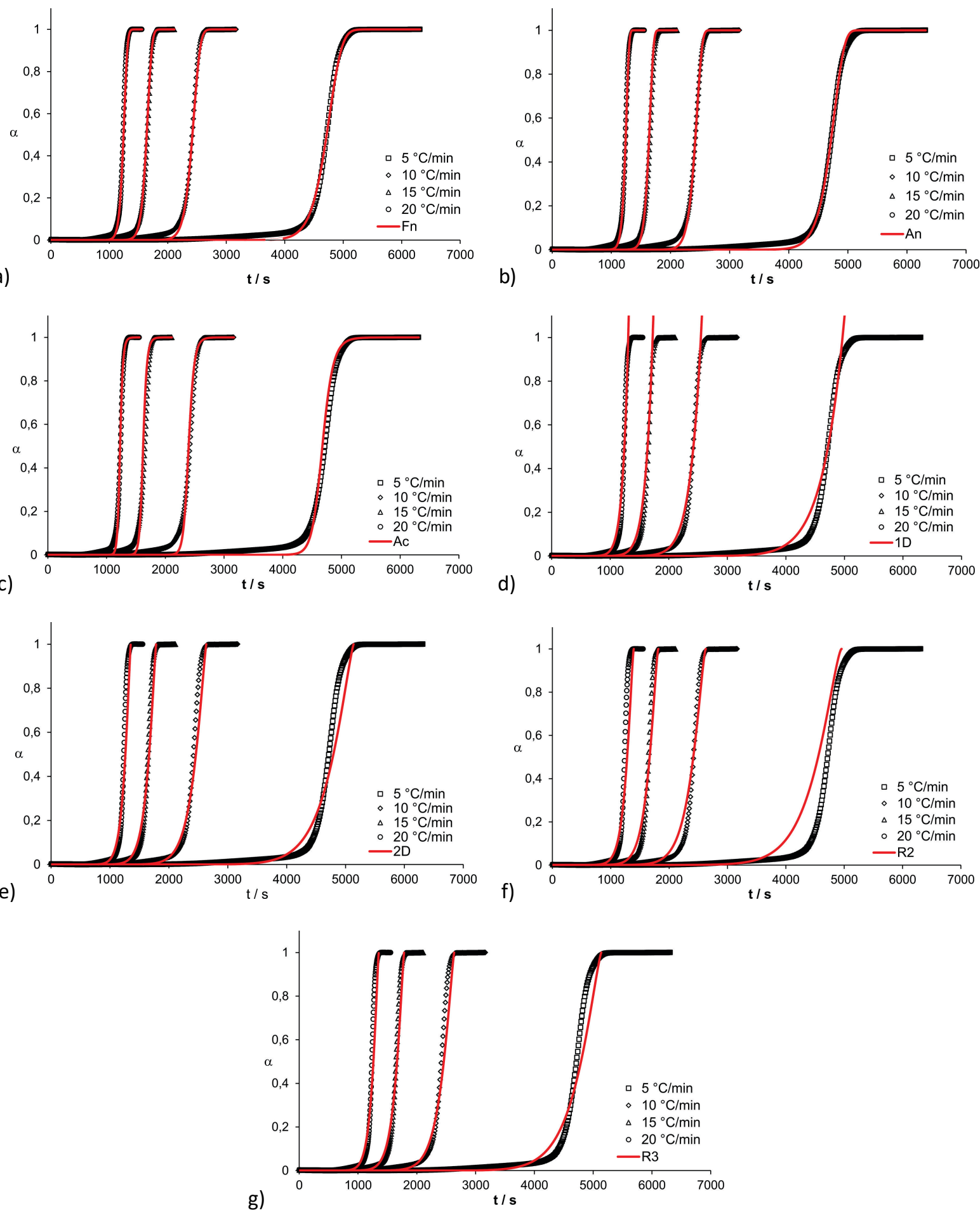

Figure 4. Model fitting of HIPS degradation using models a) Fn, b) An, c) Ac, d) 1D, e) 2D, f) R2, and g) R3.

Generally Autocatalytic model (Ac) gave lowest $E_{\mathrm{a}}$ values for all samples, including pure HIPS, but with poorest fit. Lower values of $E_{\mathrm{a}}$ of fire retarded composites were overcompensated by the difference in $A$ by a magnitude of four to five compared to HIPS thus giving overall slower degradation rate and higher thermal stability which is in accordance with previous research. ${ }^{[1,3,32]}$ It seems from Figure 5 that sample PS-20AP-4C starts to degrade earlier than pure HIPS, but it has to be taken into account that it has weight residue at $500{ }^{\circ} \mathrm{C}$ of $20 \%$ 

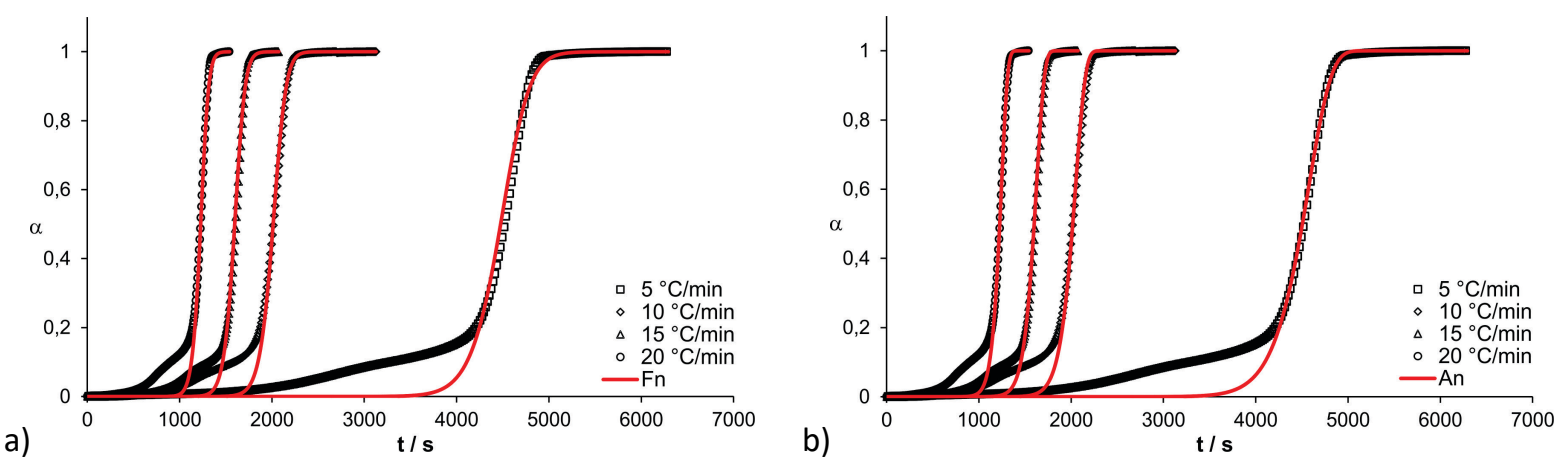

c)

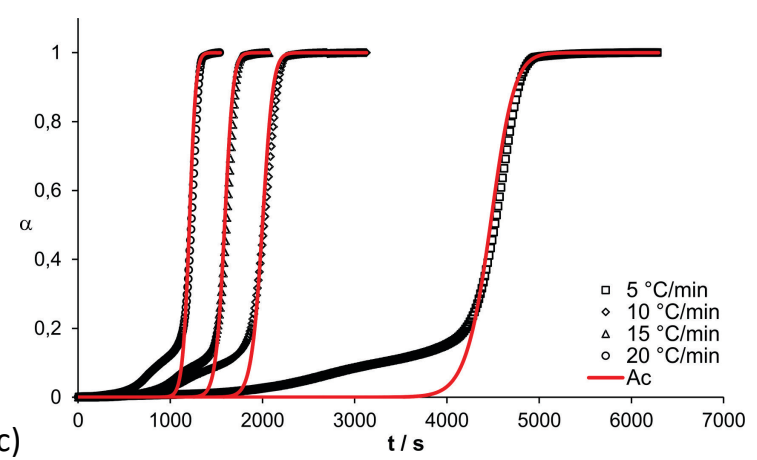

Figure 5. Experimental data and a) Fn, b) An and c) Ac model fitting of thermal degradation at different heating rates for sample PS-20AP-4C.

meaning that although it reaches certain conversion degree earlier, true mass loss is shifted to higher temperatures which was seen in Table 3.

\subsubsection{TWO STEP MODELLLING}

Since one model could not satisfyingly describe degradation rate of fire retarded composites multi-step

Table 5. Activation energy $\left(E_{\mathrm{a}}\right)$, frequency factor $(\ln A)$, true $f(\alpha)$ and RMSD values obtained for Fn, An and Ac model fitting

\begin{tabular}{|c|c|c|c|c|c|}
\hline Sample & Model & $E_{\mathrm{a}}\left(\mathrm{kJ} \mathrm{mol}^{-1}\right)$ & $\ln A\left(s^{-1}\right)$ & $f(\alpha)_{\text {true }}$ & RMSD \\
\hline & $\mathrm{Fn}$ & 268.3 & 40.2 & $(1-\alpha)^{1.17}$ & 0.013970 \\
\hline \multirow[t]{3}{*}{ PS } & An & 266.4 & 40.8 & $1.03(1-\alpha)[-\ln (1-\alpha)]^{0.03}$ & 0.014387 \\
\hline & $A c$ & 261.1 & 42.1 & $\alpha^{0.5}(1-\alpha)^{1.63}$ & 0.029471 \\
\hline & $\mathrm{Fn}$ & 244.1 & 35.8 & $(1-\alpha)^{1.02}$ & 0.049134 \\
\hline \multirow[t]{3}{*}{ PS-8A-8P } & An & 268.2 & 38.6 & $1.04(1-\alpha)[-\ln (1-\alpha)]^{0.04}$ & 0.050594 \\
\hline & $A c$ & 225.6 & 34.1 & $\alpha^{0.4}(1-\alpha)^{1.60}$ & 0.054543 \\
\hline & $\mathrm{Fn}$ & 264.3 & 36.3 & $(1-\alpha)^{1.20}$ & 0.034942 \\
\hline \multirow[t]{3}{*}{ PS-4A-20AP } & An & 266.8 & 38.3 & $0.80(1-\alpha)[-\ln (1-\alpha)]^{-0.25}$ & 0.029830 \\
\hline & $A c$ & 245.4 & 37.6 & $\alpha^{0.25}(1-\alpha)^{1.89}$ & 0.038841 \\
\hline & $\mathrm{Fn}$ & 265.8 & 36.7 & $(1-\alpha)^{1.46}$ & 0.028500 \\
\hline \multirow[t]{3}{*}{ PS-4A-200P } & An & 267.8 & 38.8 & $0.72(1-\alpha)[-\ln (1-\alpha)]^{-0.39}$ & 0.021606 \\
\hline & Ac & 265.4 & 37.6 & $\alpha^{0.3}(1-\alpha)^{2.00}$ & 0.038714 \\
\hline & $\mathrm{Fn}$ & 236.4 & 36.5 & $(1-\alpha)^{1.47}$ & 0.046736 \\
\hline \multirow[t]{2}{*}{ PS-20AP-4C } & An & 265.2 & 39.0 & $0.73(1-\alpha)[-\ln (1-\alpha)]^{-0.37}$ & 0.044072 \\
\hline & $A c$ & 226.1 & 36.1 & $\alpha^{0.21}(1-\alpha)^{1.40}$ & 0.055126 \\
\hline
\end{tabular}




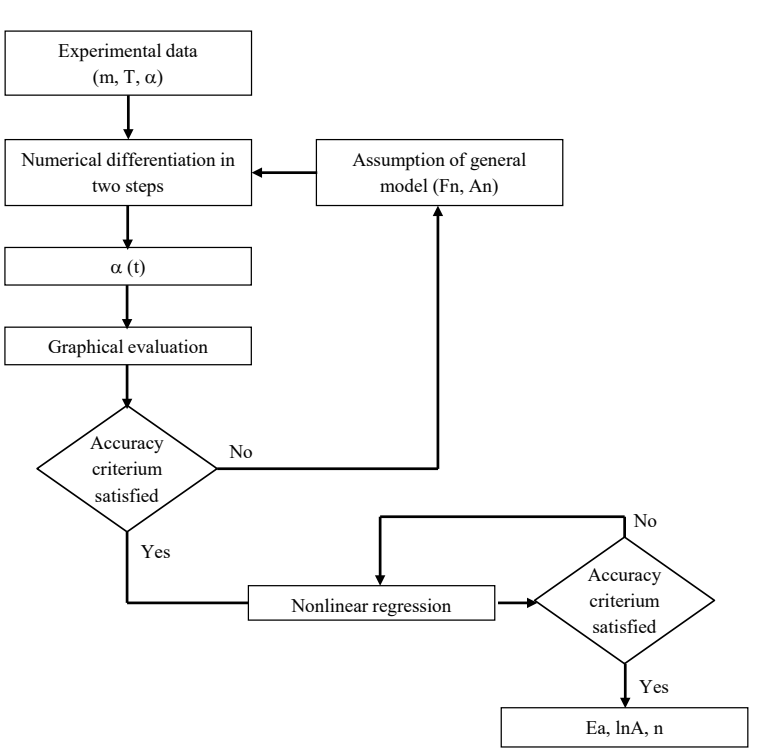

Figure 6. Flow chart of thermal degradation modelling with two models.

mechanism was chosen by exploring several alternative mechanisms and finding the one that yields the lowest value of RMSD. Approach to two step modelling is shown in Figure 6. Only models that gave a good fit (based solely on graphical evaluation) for first and second stage of degradation were chosen for further nonlinear regression. On Figure 7 degradation rate vs. conversion of sample PS-20AP-4C is again shown as an example. It can be seen that degradation occurs in two distinctive steps. Because of that model calculations in first step were performed with bordering values.

Model one made calculations from $\alpha=0$ to certain set point value of $\alpha$, while model two made calculation from that set point to $\alpha=1$. Set point was chosen as inflection point in Figure 7 which marks the end of first degradation step and start of second step. For comparison pure HIPS is also shown where it can be seen that degradation occurs in only one step. That value was different for every individual composite and it was between $\alpha$ value of 0.09 and 0.12 . As Autocatalytic model gave the poorest fit in one step modelling it was excluded from further work and only Fn and An models in different combinations were used (Table 6).

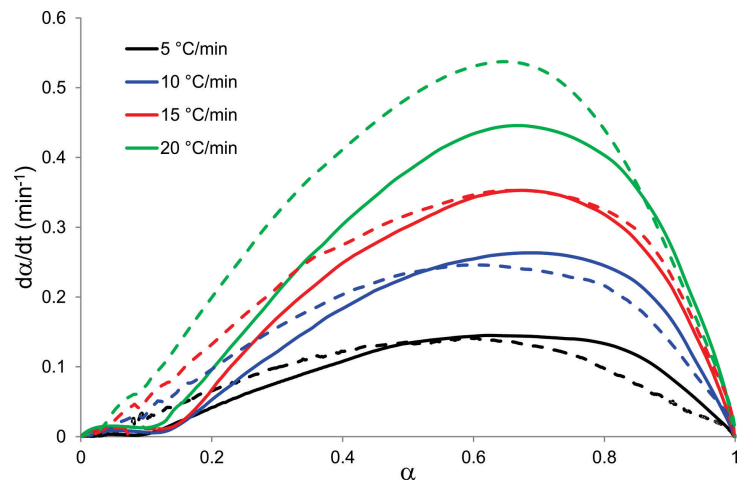

Figure 7. Experimental degradation rate dependence on degree of conversion for pure HIPS (dotted line) and sample PS-20AP-4C (full line).

Table 6. Applied combinations of models for first and second degree of thermal degradation

\begin{tabular}{cc}
\hline 1st step & 2nd step \\
\hline Reaction order $(F n)$ & Reaction order $(F n)$ \\
Reaction order $(F n)$ & Avrami-Erofeev $(A n)$ \\
Avrami-Erofeev $(A n)$ & Reaction order $(F n)$ \\
Avrami-Erofeev $(A n)$ & Avrami-Erofeev $(A n)$ \\
\hline
\end{tabular}

Fit of experimental and model calculated data is shown in Figure 8, again for sample PS-20AP-4C as an example, while RMSD values for all samples are listed in Table 7. It can be seen from Figure 8 much better agreement of model and experimental date when compared to single model approach, seen in Figure 3. RMSD values shown in Table 7 are 3 to 5 times lower than those obtained by only one model. Sample PS-4A-20AP had RMSD 0.011 when Avrami-Erofeev mechanism was used in first step and Reaction order in second step. For the same sample best fit with single model had RMSD value of 0.030 (An mechanism). Sample PS-8A-8P had worst fit in single step modelling with RMSD 0.049 while combination of An model in first and second step gave RMSD of just 0.010 . It can be seen also from Table 7 that while the all other

Table 7. RMSD values obtained for different combinations of model in first and second degree of degradation

\begin{tabular}{ccccc}
\hline & $F n+F n$ & $F n+A n$ & $A n+F n$ & $A n+A n$ \\
\hline PS-8A-8P & 0.011202 & 0.016955 & 0.010422 & 0.010033 \\
PS-4A-20AP & 0.011749 & 0.020514 & 0.011162 & 0.012670 \\
PS-4A-20OP & 0.010159 & 0.021410 & 0.011668 & 0.011341 \\
PS-20AP-4C & 0.014582 & 0.025805 & 0.011023 & 0.006624 \\
Avg. Value & 0.011923 & 0.021171 & 0.011069 & 0.010167 \\
\hline
\end{tabular}


a)
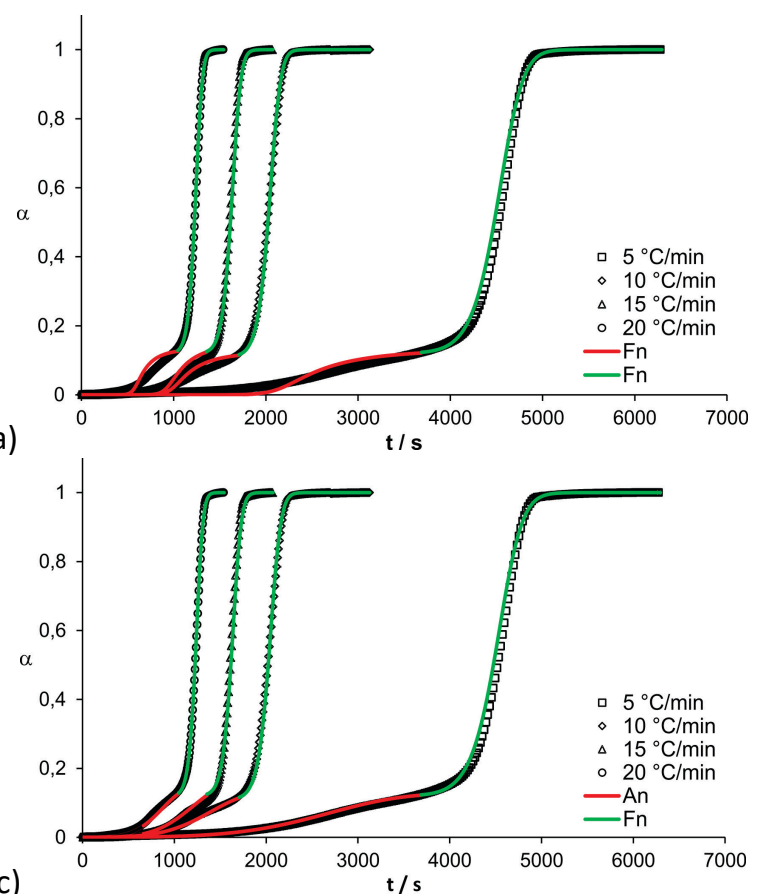

b)

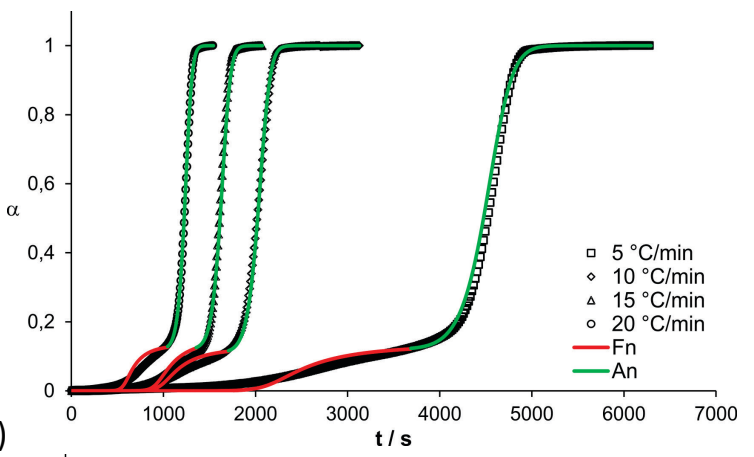

d)

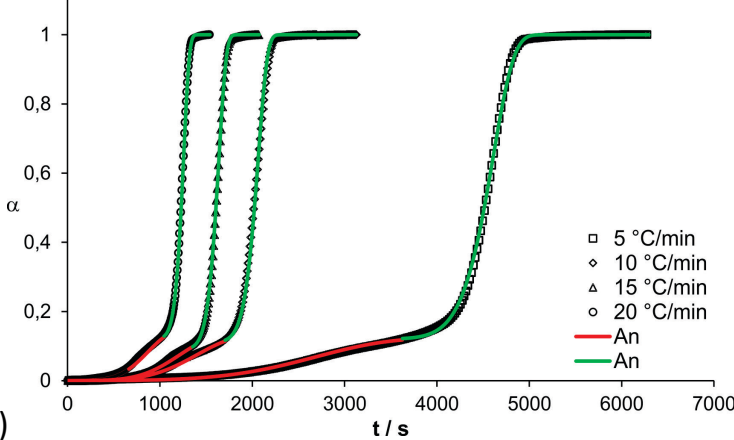

Figure 8. Experimental data and model fitting of following combinations of models: a) $F n+F n, b) F n+A n, c) A n+F n, d) A n+A n$ for sample PS-20AP-4C.

combinations gave similar results with average RMSD values $0.010-0.011 \mathrm{Fn}+\mathrm{An}$ combination had almost double RMSD value.

Kinetic parameters obtained by two step modelling are shown in Table 8. Results are shown for the model combination with the best fit. In this case activation energy for the first step is between 172 and $186 \mathrm{kJmol}^{-1}$ while Ea for the second step is between 242 and $268 \mathrm{~kJ} \mathrm{~mol}^{-1}$.

\section{CONCLUSIONS}

In this work kinetics of degradation of pure HIPS and HIPS nanocomposites with three types of phosphate and polyphosphate flame retardants was investigated.
Isoconversional Friedman and Kissinger-Akahira-Sunose methods showed that degradation of pure polymer is simple process and it was possible to obtain good fit of model and experimental data with Reaction order and Avrami-Erofeev mechanisms. On the other hand, for diffusion and phase boundary mechanisms it was not possible to obtain fit at all, meaning that thermal degradation of HIPS is not under control of those processes. Dependence of $\alpha$ vs. T in isoconversional methods for nanocomposites suggested more complex degradation mechanism than for pure HIPS. In this case single model fitting did not give satisfying fit at lower conversions. Two stage modelling provided much better agreement of model and experimental data. All combinations of Reaction order

Table 8. Activation energy $\left(E_{\mathrm{a}}\right)$, frequency factor $(\ln A)$ and real $f(\alpha)$ obtained for models with best fit (lowest RMSD value)

\begin{tabular}{|c|c|c|c|c|c|}
\hline Sample & Model & $\alpha$ & $E_{\mathrm{a}}(\mathrm{kJ} \mathrm{mol}-1)$ & $\ln A\left(s^{-1}\right)$ & $f(\alpha)_{\text {real }}$ \\
\hline \multirow{2}{*}{ PS-8A-8P } & An & $0-0.12$ & 186.3 & 30.1 & $0.24(1-\alpha)[-\ln (1-\alpha)]^{-3.13}$ \\
\hline & An & $0.12-1$ & 241.9 & 40.2 & $1.07(1-\alpha)[-\ln (1-\alpha)]^{0.07}$ \\
\hline \multirow{2}{*}{ PS-4A-20AP } & An & $0-0.09$ & 175.0 & 29.7 & $0.25(1-\alpha)[-\ln (1-\alpha)]^{-3.00}$ \\
\hline & $\mathrm{Fn}$ & $0.09-1$ & 267.7 & 40.4 & $(1-\alpha)^{1.21}$ \\
\hline \multirow{2}{*}{ PS-4A-200P } & $\mathrm{Fn}$ & $0-0.11$ & 177.0 & 31.7 & $(1-\alpha)^{4.10}$ \\
\hline & $\mathrm{Fn}$ & $0.11-1$ & 265.5 & 40.6 & $(1-\alpha)^{1.40}$ \\
\hline \multirow{2}{*}{ PS-20 AP-4C } & An & $0-0.11$ & 172.0 & 30.7 & $0.25(1-\alpha)[-\ln (1-\alpha)]^{-3.17}$ \\
\hline & An & $0.11-1$ & 258.7 & 40.6 & $0.80(1-\alpha)[-\ln (1-\alpha)]^{-0.25}$ \\
\hline
\end{tabular}


and Avrami-Erofeev mechanisms gave rather similar results, with the exception of combination of Fn in first step and $\mathrm{An}$ in second step which was the most inaccurate.

Acknowledgment. This study was supported by the Ministry of Science, Education and Sports of the Republic of Croatia (grant numbers 125-1252971-2575, 125-0821504-1976).

\section{REFERENCES}

[1] Z. Katančić, J. Travaš-Sejdić, Z. Hrnjak-Murgić, Polym. Degrad. Stab. 2011, 96, 2104.

[2] B. H. Cipiriano, T. Kashiwagi, S. R. Raghavan, Y. Yang, E. A. Grulke, K. Yamamoto, J. R. Shields, J. F. Douglas, Polymer 2007, 48, 6086.

[3] Z. Katančić, J. Travaš-Sejdić, Z. Hrnjak-Murgić, J. Jelenčić, J. Elastomers Plast. 2014, 46(3), 233.

[4] J. R. Ebdon, B. J. Hunt, P. Joseph, Polym. Degrad. Stab. 2004, 83, 1818.

[5] Y.-W. Yan, J.-Q. Huang, Y.-H. Guan, K. Shang, R.-K. Yian, Y-Z. Wang, Polym. Degrad. Stab. 2014, 99, 35.

[6] G. Madras, B. J. McCoy, Ind. Eng. Chem. Res. 1999, 38, 352.

[7] V. Mamleev, S. Bourbigot, J. Yvon, J. Anal. Appl. Pyrolysis 2007, 80, 151.

[8] P. Paik, K. K. Kar, Mater. Chem. Phys. 2009, 113, 953.

[9] C. Reverte, J. L. Dirion, M. Cabassud, J. Anal. Appl. Pyrolysis 2007, 79, 297.

[10] P. Budrugeac, E. Segal, Polym. Degrad. Stab. 2008, 93, 1073.

[11] P. Budrugeac, Polym. Degrad. Stab. 2005, 89, 265.

[12] L. A. Perez-Maqueda, P.E. Sanchez-Jimenez, J.M. Criado, Polymer 2005, 46, 2950.

[13] S. Vyazovkin, N. Sbirrazzuoli, Macromol. Rapid Commun. 2006, 27, 1515.

[14] B. J. McCoy, G. Madras, Chem. Eng. Sci. 2001, 56, 2831.

[15] A. Khawam, D. R. Flanagan DR, J. Phys. Chem. B, 2006, 110, 17315.

[16] N. Koga, H. Tanaka, Thermochim. Acta 2002, 388, 41.

[17] A. Khawam, D. R. Flanagan, J. Pharm. Sci. 2006, 95, 472.
[18] J. Pielichowski, J. Njuguna, Thermal degradation of polimeric materials, Rapra Technology Ltd., Shawbury, 2005, p. 31.

[19] P. Simon, Z. Cibulkova, P. Thomas, J. Therm. Anal. Calorim. 2005, 80, 381.

[20] S. Vyazovkin, Model-free kinetics - staying free of multiplying entities without necessity, J. Therm. Anal. Calorim. 2006, 83, 45.

[21] H. Bockhorn, A. Hornung, U. Hornung, D. Schwaller, J. Anal. Appl. Pyrolysis 1999, 48, 93.

[22] J. A. Conesa, A. Marcilla, J. A. Caballero, R. Font, J. Anal. Appl. Pyrolysis 2001, 58, 617.

[23] A. Marongiu, T. Faravelli, E. Ranzi, J. Anal. Appl. Pyrolysis 2007, 78, 343.

[24] Z. M. Gao, I. Amasaki, M. Nakada, J. Anal. Appl. Pyrolysis 2003, 67, 1.

[25] L. Lu, H. Y. Yu, S. F. Wang, Y. Zhang, J. Appl. Polym. Sci. 2009, 112, 24.

[26] A. Al-Mulla, H. I. Shaban, Int. J. Polymer. Mater. 2008, 57, 275.

[27] N. Garcia, M. Hoyos, J. Guzman, P. Tiemblo, Polym. Degrad. Stab. 2009, 94, 39.

[28] M. Erceg, T. Kovačić, S. Perinović, Thermochim. Acta 2008, 476, 44.

[29] S. Vyazovkin, A. K. Burnham, J. M. Criado, L. A. PérezMaqueda, C. Popescu, N. Sbirrazzuoli, Thermochim. Acta 2011, 520, 1.

[30] N. Sbirazzuoli, Y. Girault, L. Elégant, Thermochim. Acta 1997, 293, 25.

[31] H.L. Friedman, J. Polym. Sci., Polym. Symp. 1964, 6PC, 183.

[32] Z. Katančić, J. Travaš-Sejdić, Z. Hrnjak-Murgić, Polym. Plast. Technol. Eng. 2014, 53, 1487.

[33] X. Guoxi, L. Rui, T. Qinhu, L. Jinghua, J. Appl. Polym. Sci. 1999, 73, 1139.

[34] A. Marcilla, M. Beltran, Polym. Degrad. Stab. 1995, 50, 117.

[35] S. Vyazovkin, A. I. Lesnikovich, Thermochim. Acta 1990, 165, 273.

[36] G. Grause, J. Ishibashi, T. Kameda, T. Bhaskar, T. Yoshioka, Polym. Degrad. Stab. 2010, 95, 1129. 